\title{
ИНТЕРАКТИВНОСТЬ И КОМПЬЮТЕРНЫЕ ТЕХНОЛОГИИ В ИСКУССТВЕ
}

\begin{abstract}
Аннотация. В центре данного исследования лежит понятие интерактивности. Проблема состоит в том, что интерактивность не имеет четкого определения, она понимается по-разному в зависимости от контекста. Сегодня многие произведения искусства характеризуются как интерактивные. При рассмотрении этих произведений становится очевидным, что даже в рамках одной области интерактивность чрезвычайно многолика. Автор рассматривает различные произведения искусства, созданные путем применения компьютерных технологий, с тем, чтобы установить, какие из них интерактивные и что их делает таковыми.

В статье использованы различные методы. Прежде всего, исторический, который помогает проследить, как понятие интерактивности развивалось в течение XIX и XX веков. Автор анализирует и соотносит как отечественные, так и зарубежные исследования, посвященные феномену интерактивности. Вместе с тем автор проводит сравнительный анализ различных творческих программ. В статье соотносится традиционное понятие сотворчества с инновационным понятием интерактивности. Автор выделяет два вида творческих программ (замкнутые и открытые) с тем, чтобы точно определить, в каких случаях пользовательская интеракция с программой носит по-настоящему творческий характер. Таким образом, автор обосновывает позицию, что некоторые компьютерные программы действительно способны обеспечить пользователю платформу для полноченного творчества.

Ключевые слова: компьютерные технологии, компьютерное искусство, интерактивность, интерактивное искусство, творческая программа, графический редактор, сотворчество, авторство, творчество программиста, творчество пользователя.
\end{abstract}

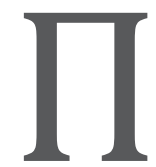
онятие «интерактивность» сегодня стало весьма популярным и часто употребляемым в сфере творчества, педагогики и коммуникаций. Современные исследователи отмечают, что универсальный характер «интерактивности» препятствует их попыткам найти точное определение данному понятию. Канадский философ Д. Лопес к примеру пишет об интерактивности следующее: «Проблема с понятием "интерактивность" заключается не в том, что оно ничего не значит. Настоящая проблема кроется в том, что оно применимо к слишком большому количеству вещей, относящихся к самым разным ситуациям, поэтому сформулировать одно подходящее для всех случаев определение очень сложно» ${ }^{1}$.

В самом широком понимании интерактивность - это понятие, раскрывающее характер и сте-

Lopes D. A Philosophy of Computer Art. London: Routledge, 2009. P. 36. пень взаимодействия между объектами (interaction в переводе с английского - взаимодействие). При этом можно отметить, что большинство людей ассоциирует понятие интерактивности так или иначе с компьютерной техникой, виртуальной реальностью, экспериментами в области современного искусства. Кибернетика и современное искусство это две основные области, в которых понятие интерактивности сегодня активно разрабатывается.

В кибернетическом контексте выделилось несколько различных подходов к определению понятия интерактивности. Отечественный исследователь Д.В.Галкин в своей научной статье «Понять интерактивность: кибернетика в зеркале эстетики» ${ }^{2}$ отметил, что «кибернетическое пред-

2 Галкин Д.В. Понять интерактивность: кибернетика в зеркале эстетики // Сайт междисциплинарного сборника статей «Гуманитарная иформатика». (http://huminf.tsu.ru/jurnal/ vol5/gdv_kibernetika_estetika/). 


\section{Философия и культура 6(78) • 2014}

ставление об интерактивности претерпело значительные изменения: от чисто технического к биологическому и далее когнитивно-социальному». Самые первые ученые-кибернетики, так называемые «кибернетики первого порядка» (Н. Винер) рассматривают интерактивность как «процессуальное описание механизма обратной связи в живых и неживых системах», а также как «механизм активной адаптации системы к ее внешней среде». «Кибернетики второго порядка» (Ф. Варелла, Р. Матурана) работают с организмами и социальными системами, признавая их независимость в процессе взаимодействия с другим агентом (наблюдателем), при этом система рассматривается как продукт взаимодействия знания наблюдателя и объекта.

Кроме того, как мы уже отметили, термин «интерактивность» активно используется в области современного искусства, где под интеракцией, прежде всего, понимают взаимодействие аудитории с произведением искусства. Впрочем, идея интерактивности в искусстве совсем не нова. Более того, если задуматься, то становиться очевидным, что любое произведение подразумевает участие аудитории. Когда реципиенты смотрят или слушают, они уже оказываются вовлеченными в процесс эстетического освоения предложенного им произведения. При этом заинтересованные реципиенты чаще всего не ограничиваются простым «смотрением» или «слушаньем», они активно анализируют, обсуждают и пробуют интерпретировать представленное их вниманию произведение. В отечественной эстетике (в работах В.Ф. Асмуса, А.Ф. Лосева, М.С. Кагана) подобное активное восприятие уже давно трактовалось как сотворческое по своей природе; и в понятии эстетического освоения творческий элемент понимался как необходимый и закономерный.

Авторитетный исследователь в области компьютерной техники, автор большого количества научных статей и книг Лев Манович отмечает следующее: «Все классические и тем более современные произведения “интерактивны”, они требуют от зрителя домысливать и вносить недостающую информацию (к примеру, опущенный текст в литературном повествовании; отсутствующие элементы в модернистских картинах), водить взглядом и рассматривать произведения (изобразительное искусство и киноискусство) или даже передвигаться всем телом (скульптура, архитектура)»3.

\footnotetext{
3 Manovich L. On totalitarian interactivity (notes from the enemy of the people), 1996. (http://manovich.net/TEXT/totalitarian.htm).
}

Действительно, как и заметил Лев Манович, все произведения в каком-то смысле интерактивны, однако только в двадцатом веке вводится такое понятие как «интерактивное искусство». Попробуем проследить, как понятие интерактивности развивалось в творческом контексте. В XIX веке художники начинают активно размышлять над тем, какое значение для творца имеют зрители и как они могут взаимодействовать с произведением. Научно-техническая революция имела большое количество самых разных последствий для нашего общества, в том числе она повлияла на мир изобразительного искусства, способствуя формированию нового понимания света и визуальной перцепции. Фотография начинает приобретать популярность. Вместе с тем, художники, находясь в работе над произведением изобразительного искусства, постепенно перестают стремиться к точному воспроизведению реальности. Цель художника теперь состоит не в том, чтобы достигнуть полного сходства между реальным объектом и его изображением на картине, а в том, чтобы поделиться со зрителем собственным восприятием реальности, позволить зрителю взглянуть на объект сквозь призму ощущений и переживаний художника.

Таким образом, фокус внимания художников смещается, и постепенно формируется мнение, что зритель - это важный участник творческого процесса. Импрессионисты, а позднее и пуантилисты были убеждены в том, что зрители, воспринимая произведение искусства, вовлекаются художником в творческий процесс. Таким образом, уже в XIX веке зритель начинает признаваться важным участником творческого процесса, без которого существование самого произведения теряет значение.

B XX веке художники продолжают размышлять над значением аудитории в творческом процессе. Знаменитый Марсель Дюшан был убежден в том, что сами зрители создают картину, и рассматривал процесс взаимодействия художника и аудитории, их диалог «как саму основу процесса создания образа: произведение лишь точка отсчета, после которой необходимо уже договариваться, предполагая Другого...» ${ }^{4}$.

Художники-кубисты стремятся к тому, чтобы «анализировать наше визуальное взаимодействие

4 Буррио Н. Эстетика взаимодействия // Культурный Альянс. Проект Марата Гельмана. (http://www.guelman.ru/ $\mathrm{xz} / 362 / \mathrm{xx} 28 / \mathrm{x} 2808 . \mathrm{htm})$. 
с миром через посредство элементов повседневной жизни (угол стола, трубки и гитары) и, исходя из ментального реализма, воссоздать динамичный характер нашего знания объекта...» ${ }^{5}$. Таким образом, художники исследуют возможности человека взаимодействовать с окружающей его реальностью, изучают динамичный процесс освоения этой реальности.

Затем начинают появляться работы, которые не просто имитируют и создают ощущение движения, а на самом деле двигаются, видоизменяются и трансформируются. Скульптуры перестают быть неподвижными. Художники работают над различными инсталляциями, идет активное развитие кинетического искусства. Группа синтетических искусств значительно расширяется. Новые произведения искусства требуют более активного взаимодействия с ними, чем когда-либо раньше. Зритель вовлекается в пространственно-временной процесс эстетического освоения произведений.

Рассматривая идею интерактивности в искусстве, исследователь С. В. Ерохин обращает особое внимание на эксперименты Л. Мохой-Надя и его так называемые «Телефонные картины» ${ }^{6}$ (Telephone Pictures, 1922). «Телефонные картины» заложили основу направления, получившего впоследствии название «телекоммуникационное искусство» («Telecommunications Art»). По мнению С.В. Ерохина, именно в рамках телекоммуникационного искусства «произошла «ломка» традиционных отношений между реципиентом и произведением искусства, обусловленная возможностью получения «удаленного» эстетического опыта» ${ }^{7}$.

По мере развития компьютерных технологий, их область применения расширяется, они постепенно вводятся в самые разные сферы человеческой деятельности, в том числе и творческие. Когда происходит пересечение областей кибернетики и искусства, вопрос интерактивности еще больше осложняется. Как мы видим, понятие интерактивности в искусстве прежде всего связано с аудиторией; интеракция - это процесс

\footnotetext{
5 Там же.

6 «Телефонные картины» были выполнены из эмалированного металла на фабрике вывесок по заказу, продиктованному художником по телефону.

Ерохин С.В. Эстетика цифрового изобразительного искусства. СПб.: Алтейя, 2010. С. 150.
}

взаимодействия аудитории с произведением. Но как именно меняется понятие интерактивности в современном контексте, как оно трансформируется под влиянием компьютерного развития? Обладают ли произведения, выполненные с помощью компьютера какой-то «особенной» интерактивностью?

В контексте творческих практик, зависящих от компьютерной техники, интерактивность интерпретируется по-разному. Как отмечает Д.В.Галкин, «в кибернетическом искусстве художники трактуют интерактивность по-разному: как игру-взаимодействие с аудиторией, как реакцию на динамику окружающей среды или самодеструкцию машины». Очевидно, что даже в рамках одной области интерактивность понимается по-разному. При этом большинство современных исследователей рассматривают интерактивность одним из двух способов: 1) как взаимодействие человека непосредственно с компьютером; 2) как взаимодействие человека с другим человеком, осуществляющееся с использованием компьютерных технологий.

Именно творческое взаимодействие двух индивидов, осуществляемое с помощью компьютерных технологий вызывает у нас наибольший интерес, поскольку, сотворчество, а следовательно и по-настоящему творческое взаимодействие между человеком и машиной невозможно на данном этапе развития компьютерных технологий. Как доказывает Д.В. Галкин, современная ситуация в искусстве взывает к пересмотру понятия интерактивности, а также характеризуется стремлением совершить «переход от простой реактивности к креативности». Ученый считает, что на данном этапе развития техники взаимодействие человека с машиной исключено, поскольку полноценная творческая интеракция предполагает в первую очередь обязательное наличие перцептивных способностей у всех участников творческого процесса. В этом состоит одна из причин, по которым компьютер не способен к сотворчеству с человеком. В данном вопросе мы полностью согласны с Д.В. Галкиным. «Слово «интерактивный» стало синонимом компьютерных технологий, неким самоочевидным аспектом «новых медиа» во всем их многообразии. Однако в большинстве случаев цифровая интерактивность касается лишь узкого аспекта реактивности и обратной связи как инструмента контроля. Компьютеры пока нельзя назвать интерактивными, поскольку они еще не достигли того уровня 


\section{Философия и культура 6(78) • 2014}

взаимодействия, где интерактивность означает креативность или автопоэтику смерти» ${ }^{8}$.

Несмотря на то, что по-настоящему интерактивный (а значит автономный, творческий) компьютер не может существовать на данном этапе развития компьютерной техники, в контексте современного искусства мы очень часто слышим об «интерактивных произведениях компьютерного искусства». Что же в данном случае подразумевается под интерактивностью? Что понимается под интерактивным произведением? Ученый С.В. Ерохин предлагает простое определение, с которым сложно не согласиться, интерактивность - «открытость художественного произведения для продолжения» ${ }^{9}$. Из данного определения следует, что интеракция с произведением - это продолжение творческого процесса. Другими словами, интеракция - это взаимодействие с произведением, которое в сущности является взаимодействием между создателем произведения и его сотворчески действующим зрителем. В области современного искусства происходит постепенный переход от «субъектно-объектного к субъектно-субъектному взаимодействию», а художник из «создателя произведения» превращается в «инициатора открытого коммуникативного поля, в котором осуществляется креативное взаимодействие» ${ }^{10}$. Таким образом, любая творческая интеракция сводится к взаимодействию двух людей.

Взаимодействие между людьми всегда было и будет возможным, а современный компьютер способен выступать в роли посредника творческой интеракции людей, выводя взаимодействие двух индивидов (программиста и пользователя) на новый уровень. Программист, используя компьютер, создает творческие программы и таким образом открывает творческий диалог, к которому позднее присоединяется пользователь программы. Сотворчество двух индивидов (программиста и пользователя) подразумевает, что программист сначала создает базовую основу произведения (программу), после чего аудитория пользователей посредством использования этой программы

\footnotetext{
8 Галкин Д.В. Понять интерактивность: кибернетика в зеркале эстетики // Сайт междисциплинарного сборника статей «Гуманитарная информатика». (http://huminf.tsu.ru/jurnal/ vol5/gdv_kibernetika_estetika/).

9 Ерохин С.В. Эстетика цифрового изобразительного искусства. СПб.: Алтейя, 2010. С. 150.

10 Там же.
}

как бы «раскрывает» ее и вместе с тем создает собственный творческий продукт.

В контексте компьютерного искусства все чаще начинают говорить об аудитории не просто как об активных участниках творческого процесса, но как о полноценных соавторах художника. Так, рассматривая проблему интерактивности, С.В. Ерохин говорит о том, что современные тенденции в искусстве способствуют развитию творческих способностей зрителя, а в ходе взаимодействия с произведением искусства реципиент превращается в соавтора: «интерактивность искусства предъявляет более высокие требования к “квалификации" реципиента, которая должна обеспечивать возможность его полноценного участия в качестве соавтора художественного произведения» ${ }^{11}$. Однако правомерно ли говорить о возможности сотворчества в отношении всех интерактивных произведений? Как мы уже отмечали, многие произведения могут быть признаны в той или иной степени «интерактивными», но лишь некоторые из них дают реципиенту реальную возможность творчески сотрудничать с художником.

Современный компьютер способен выступать в роли посредника творческой интеракции людей (например, программиста и пользователя), выводя взаимодействие двух индивидов на новый уровень. Однако это еще не означает, что аудитория способна вступить в сотворчество с программистом. Чем в действительности является продукт пользовательской работы с программой? Можно ли его считать независимым от программы произведением искусства? Могут ли пользователи, используя одну и ту же программу, создавать многочисленные произведения ${ }^{12}$ ? Все это зависит от самой программы, от того какие возможности в нее изначально были вложены программистом. Все это приводит к необходимости выделить два принципиально различных вида программ, создаваемых в художественно-творческих целях: замкнутые и открытые программы.

Интеракция с замкнутой программой характеризуется нелинейностью, однако эта нелинейность всегда лимитирована и сводится к тому, что пользователь программы просто следует сцена-

\footnotetext{
11 Там же. С. 190.

12 Эти вопросы подробно рассматриваются в другой статье автора: Ханолайнен Д.П. Эстетика воспроизводимого в современном искусстве // Философия и культура. 2013. № 11. C. $1598-1606$.
} 
рию, определенному программистом. Очевидно, что процесс интеракции с замкнутой программой не может считаться творчеством, поскольку в таких условиях пользователь оказывается полностью подчиненным воле программиста. При этом замкнутость не является синонимом примитивности. Некоторые замкнутые программы способны «реагировать» на каждого отдельного пользователя по-разному. Таким образом, программа может предлагать каждому пользователю уникальный опыт, однако функция замкнутой программы всегда четко определена, а значит, способы интеракции с ней ограничены, именно в этом и состоит замкнутость - замкнутая программа полностью контролирует процесс интеракции, сдерживая тем самым творческую инициативу пользователя. Иными словами, программа не позволяет пользователю взаимодействовать с ней ни каким другим способом кроме того, который был предусмотрен программистом.

Открытая же программа способна предоставить пользователю свободу и возможность проявить свою творческую инициативу. Можно даже сказать, что пользователь открытой программы перестает быть просто пользователем, он поднимается до уровня художника. Количество возможных вариантов и исходов взаимодействия с программой бесконечно. Открытая программа не ограничивает пользовательскую креативность, пользователь сам решает как и для чего использовать программу. Таким образом, открытые программы предоставляют пользователю настоящую платформу для творчества, а результатом пользовательской интеракции с программой становится новое произведение.

К числу открытых можно отнести такие популярные графические редакторы, как Adobe Photoshop и CorelDRAW, при этом, когда мы говорим о творческих работах, созданных путем использования графических редакторов, возникает вопрос о том, кто должен признаваться автором таких работ: программист (создатель графического редактора) или пользователь (непосредственный создатель творческой работы). Уместно ли говорить о таких творческих работах как о продукте сотворчества программиста и пользователя?

Одним из тех, кто резко заострил внимание общественности на роли графических редакторов в современном искусстве и на том, что без творческой деятельности программистов невозможно творчество художников-пользователей, был
Эдриан Уорд (Adrian Ward), английский художник, музыкант и программист. Э. Уорд возглавляет Signwave, независимую компанию разработчиков программного обеспечения. В 1999 и 2000 гадах эта компания выпустила два графических редактора, Auto-shop и Auto-illustrator соответственно, которые были разработаны наподобие чрезвычайно популярных Adobe Photoshop и Adobe Illustrator. Однако, Auto-illustrator и Auto-shop - это не просто имитация всем известных пакетов программного обеспечения, принципиальная разница заключается в том, что Auto-illustrator и Auto-shop являются программами закрытого типа. Эти программы лишают пользователя возможности принимать большую часть творческих решений. Программы как бы перенимают на себя творческую функцию художника.

По заявлениям самого Э. Уорда, он и его компания Signwave разработали и создали своего рода программы-пародии, которые, по сравнению с традиционными графическими редакторами, в большей степени автономны. Творческий процесс определяется не художником-пользователем, а алгоритмами, заложенными разработчиками в программу. Э. Уорд подчеркивает, что ни один из ныне существующих графических редакторов не дает пользователю полной творческой свободы. За основу своих экспериментов Э. Уорд намеренно взял самые популярные среди современных художников и дизайнеров графические редакторы Adobe Photoshop и Adobe Illustrator, что бы на их примере показать, насколько результат работы пользователей с программой зависит от возможностей и ограничений самой программы, от изначально заложенных в нее установок. Своим утрированным версиям программ Э. Уорд дал созвучные с оригиналами названия Auto-shop и Auto-illustrator.

Кроме того, цель создания Auto-illustrator и Auto-shop заключалась в том, чтобы привлечь внимание к проблеме авторства и продемонстрировать, как художник, прибегающий к использованию коммерческих графических редакторов, делит свои творческие обязанности с создателями-программистами этих самых редакторов. Для того чтобы столкнуть пользователя лицом к лицу с данной проблемой, разработчики компании Signwave решили сопроводить каждую копию выпускаемого ими графического редактора смелым и даже вызывающим лицензионным соглашением. В нем пользователю сообщается о том, что всё, созданное средствами данного программного обеспечения, 


\section{Философия и культура 6(78) • 2014}

является продуктом совместной работы пользователя и компании Signwave, а, следовательно, любое произведение - это результат сотворчества художника и разработчиков. Только при условии принятия данного соглашения пользователь допускается к работе с программой.

Нет ничего удивительного в том, что предъявленный ультиматум вызвал волну негативной реакции. Пользователи, поставленные перед выбором, были возмущены требованием лицензионного соглашения частично передать свое авторство компании-разработчику. Соглашение в целом было воспринято, как оскорбление и даже попытка ущемить авторские права пользователей. Таким образом, компании Signwave удалось привлечь внимание пользователей к волнующей их проблеме авторства. Программы Auto-illustrator и Auto-shop, пародирующие известные всем коммерческие графические редакторы, позволили пользователям почувствовать себя на месте несправедливо отодвинутых на задний план инженеров, разработчиков, ученых и программистов, вовлеченных в непосредственное развитие как компьютерных технологий, так и современного изобразительного искусства.

В общем, позиция Эдриана Уорда и компании Signwave ясна - по его мнению, вклад истинных творцов остается недооцененным. Пользователь любого графического редактора располагает лишь ограниченным набором креативных опций. Он не может переписывать или каким-либо другим способом модифицировать заложенные программистом алгоритмы, которые определяют доступный интерфейс, словом, он не имеет возможности настраивать программу «под себя». Однако не стоит забывать, что такие графические редакторы, как Adobe Photoshop, Adobe Illustrator и CorelDRAW приобрели популярность и полюбились художникам и дизайнерам в первую очередь за свои широкие ресурсы. Каждый из этих графических редакторов, безусловно, способен предложить по-настоящему гибкий полифункциональный творческий инструментарий, требуемый художнику для полноценной реализации своих творческих задумок.

Думается, что творения Э. Уорда, а именно программы Auto-illustrator и Auto-shop, не умаляют огромного креативного потенциала своих прообразов; они призваны лишь напомнить художникупользователю о том, что его творческий инструмент (любой графический редактор) является сам по себе своего рода произведением искусств, соз- дателей которого не стоит недооценивать и попирать. Э. Уорд высмеивает надменных и горделивых пользователей, возомнивших себя художниками только потому, что им удалось найти применение продуктам чужого творчества. Вместе с тем Эдриан Уорд предостерегает пользователей графических редакторов от стандартизации своей творческой деятельности. К сожалению, это довольно распространенная проблема современных художников, когда они в попытках создания произведений искусства следуют привычному, протоптанному маршруту, впав в колею псевдотворческих манипуляций. В результате художник создает нечто шаблонное и заурядное.

Данная проблема продолжает оставаться актуальной, даже несмотря на то, что большинство современных графических редакторов способно предоставить художнику огромный источник ресурсов и средств, достаточных для того, чтобы удовлетворить даже самые обстоятельные творческие поиски. Например, ряд эффектов и фильтров Adobe Photoshop (фильтры motion blur, cutout и др.), используемые в основном для обработки цифровых фотографий, за последние несколько лет приобрели необыкновенную популярность. В результате фотографии, подвергнутые обработки данными фильтрами приобретают единообразный, унифицированный внешний вид. Именно против подобной чрезмерной стандартизации творческих процессов выступают Э. Уорд и его команда программистов.

Вместе с тем ни Э. Уорд, ни какой-либо другой деятель искусства не призывают объявить несостоявшимися произведениями искусства все работы, выполненные средствами графических редакторов. Для разрешения сложившейся ситуации художнику достаточно повысить требования, предъявляемые к своим работам. Совершенно очевидно, что изначально изобретение графических редакторов было направленно на облегчение творческих исканий художников. Создатели графических редакторов стремились превратить компьютер из мудреной и непонятной машины в простой и доступный для широкого круга художников творческий инструмент. Подобная адаптация компьютерных технологий в целях их массовой популяризации была достигнута ценой неизбежной стандартизации творческой деятельности художника.

Рисование в графическом редакторе - это полностью регулируемый, лимитированный про- 
граммой процесс, который априори не может выходить за установленные программистом рамки. Учитывая данное обстоятельство, мир изобразительного искусства допускает пересмотр некоторых критериев оценки произведений. Обращаясь к тому или иному программному обеспечению, художник вынужден принимать все те ограничения, накладываемые выбранной программой. Взамен, художник получает ряд преимуществ. В частности, художник освобождается от механического, нетворческого труда, переложив его на компьютер. Работа в графическом редакторе подразумевает рациональное использование ресурсов программы. Следовательно, умеренное использование предлагаемых программой возможностей позволяет ускорить и упростить творческий процесс.

Стремление к рационализации работы художника появилось задолго до появления компьютерных технологий. К примеру, скандально известная картина L.H.O.O.Q. Марселя Дюшана представляет собой не что иное, как открытку-репродукцию всем известного полотна, на которой художник карандашом пририсовал усы и бороду Джоконде. Марсель Дюшан выполнил картину L.H.O.O.Q. своим излюбленным методом использования «готовых» (ready-made) объектов, шокируя зрителя своим демонстративным отвержением «высокого искусства» - произведений старых мастеров. При этом, чтобы сделать свое творческое заявление, художнику не понадобилось скрупулезно перерисовывать оригинальное произведение масляными красками на холсте, создавая точную копию пародируемой Джоконды, дабы потом дорисовать ей усы и бороду. Все, что потребовалось М. Дюшану - это идея, для воплощения которой он целесообразно выбрал кратчайший и наименее трудоемкий путь.

Таким образом, рационализация творческой деятельности, а именно попытка упростить и ускорить процесс создания картины представляется оправданным шагом. Однако, использование «ускорителей» и «упростителей» допустимо лишь в определенной степени. Стремление художника сделать свою деятельность продуктивной является вполне естественным и понятным желанием. При этом умеренная и резонная рационализация не всегда тождественна следованию самому прямолинейному пути создания произведения. К числу художников, попытавшихся найти оптимальное, но трудноуловимое соотношение непринужденности и обдуманности творческих решений, можно причислить художника-аниматора Джона Уитни (John Whitney), который смог разрешить сложившуюся проблему замечательным способом.

Будучи созидательной личностью, Д. Уитни преимущественно занимался различными видами творчества, в том числе созданием абстрактных фильмов и анимации. Программирование никогда не входило в сферу его деятельности. Тем не менее, Д. Уитни испытывал тяготение к компьютерным и цифровым технологиям и хотел применять их для создания своих анимационных произведений. Заинтересованность компьютерами и разными способами их применения подтолкнула художника к сотрудничеству с учеными-программистами. Специальное программное обеспечение было разработано на заказ для Д. Уитни, которое удовлетворяло всем индивидуальным потребностям художника. Ларри Куба (Larry Cuba), один из программистов, тесно работавших с Д. Уитни, описал программное обеспечение, используемое художником, как «персональный творческий инструмент, созданный для конкретных потребностей художника».

В то время как программное обеспечение Д. Уитни представляет собой «персональный творческий инструмент», коммерческие графические редакторы являются универсальными пакетами программного обеспечения, рассчитанными на массовое производство и распространение. Совершенно очевидно, что возможность заказать персональное программное обеспечение доступна далеко не всем художникам. Тем не менее, даже общедоступные графические редакторы предоставляют широкие возможности, которых должно быть достаточно для адекватной реализации самых разнообразных творческих идей. Вместе с тем от художника требуется осознать и компетентно применить все возможности и ресурсы, предоставляемые редактором.

В заключение отметим, что по мере своего развития, компьютерные технологии распространяются на самые разные области, в том числе и на творческие. Введение компьютерных технологий в творческие области привело к столкновению двух различных понятий - традиционного и инновационного (сотворчество в искусстве и кибернетическая интерактивность). В результате рассмотрения различных примеров современных интерактивных произведений, мы пришли к выводу о необходимости разделить все компьютерные программы на два вида (открытые и замкнутые) с тем, чтобы точно определить в каких случаях 


\section{Философия и культура 6(78) • 2014}

пользовательская работа с программой носит понастоящему творческий характер. Путем прямого использования замкнутых программ невозможно создать новое произведение искусства, поскольку творческие возможности замкнутых программ слишком ограниченны. Авторство работ, выработанных с помощью замкнутых программ, безусловно принадлежит программисту. В случае с открытыми программами, авторство работ, выполненных с их помощью, в первую очередь принадлежит уже художникам-пользователям. Пользователь открытой программы обладает собственной творческой инициативой, которую он может проявить в ходе своей работы с программой. Впрочем, работа с любой программой в какой-то степени накладывает на пользователя ряд творческих ограничений. Пользователю приходится считаться с заложенными в программу правилами и ограничениями. Однако это не значит, что программист является автором всех творческих работ, полученных путем использования его программы.

Своей работой (т. е. путем программирования) программист позволяет компьютеру выступать в качестве прикладного творческого инструмента, который становится некоторым «продолжением руки» художника-пользователя, еще одной кистью в арсенале современного цифрового творца. Роль программистов в современном искусстве, и не только компьютерном, несомненно, велика. Через создаваемые ими программы осуществляется взаимодействие, творческая интеракция между различными субъектами художественного процесса.

Таким образом, один из важнейших общих признаков компьютерного искусства - программируемость, является базовой, онтологической характеристикой компьютерного произведения. Другой общий признак - интерактивность, которая дает возможность конструировать и фиксировать формы, раскрывая, реализуя также произведения, заложенные в программах закрытого типа. Интерактивность, выступающая новой формой сотворчества, проявляет себя как способ реализации возможностей компьютерной программы. Оба признака свидетельствуют о глубоком, фундаментальном отличии компьютерного искусства от традиционных способов художественного творчества, что приводит к необходимости выделения его в самостоятельный вид искусства.

\section{Список литературы:}

1. Буррио Н. Эстетика взаимодействия. // Культурный Альянс. Проект Марата Гельмана. (http://www. guelman.ru/xz/362/xx28/x2808.htm).

2. Галкин Д.В. Понять интерактивность: кибернетика в зеркале эстетики // Сайт междисциплинарного сборника статей «Гуманитарная информатика». (http://huminf.tsu.ru/jurnal/vol5/gdv_kibernetika_ estetika/).

3. Гуревич И.М. Физическая информатика - новое синтетическое научное направление // NB: Кибернетика и программирование. 2013. № 3. С. 55-74. (http://e-notabene.ru/kp/article_9133.htm).

4. Гуревич П.С. Эстетика. М.: КНОРУС, 2011.

5. Ерохин С.В. Эстетика цифрового изобразительного искусства. СПб.: Алетейя, 2010.

6. Кириллова Н.Б. Медиалогия как синтез наук // Культура и искусство. 2012. № 6. С. 71-83.

7. Смирнов Е.В. Машина Тьюринга и человек: онтогносеологический аспект компьютерной метафоры сознания // Философия и культура. 2012. № 3. С. 115-123.

8. Сморкалов А.Ю., Садовин И.А. Система переноса лекций в виртуальный мир vАсаdemia с использованием возможностей Microsoft Kinect и потоковых процессоров // Программные системы и вычислительные методы. 2013. № 4. С. 354-362.

9. Ханолайнен Д.П. Эстетика воспроизводимого в современном искусстве // Философия и культура. 2013. № 11. С. 1598-1606.

10. Юхвид А.В. Виртуальный театр: философия, искусство и технология ХХІ века // Философия и культура. 2010. № 10. С. 94-98.

11. Юхвид А.В. Философско-методологическая концепция виртуологии // Философия и культура. 2010. № 9. С. 81-85.

12. Lopes D. A Philosophy of Computer Art. London: Routledge, 2009.

13. Manovich L. On totalitarian interactivity (notes from the enemy of the people), 1996. (http://manovich.net/ TEXT/totalitarian.htm). 


\section{References (transliteration):}

1. Burrio N. Estetika vzaimodeistviya // Kul'turnyi Al'yans. Proekt Marata Gel'mana. (http://www.guelman.ru/ xz/362/xx28/x2808.htm).

2. Galkin D.V. Ponyat' interaktivnost': kibernetika v zerkale estetiki // Sait mezhdistsiplinarnogo sbornika statei «Gumanitarnaya iformatika». (http://huminf.tsu.ru/jurnal/vol5/gdv_kibernetika_estetika/).

3. Gurevich I.M. Fizicheskaya informatika - novoe sinteticheskoe nauchnoe napravlenie // NB: Kibernetika i programmirovanie. 2013. № 3. S. 55-74. (http://e-notabene.ru/kp/article_9133.htm).

4. Gurevich P.S. Estetika. M.: KNORUS, 2011.

5. Erokhin S.V. Estetika tsifrovogo izobrazitel'nogo iskusstva. SPb.: Aleteiya, 2010.

6. Kirillova N.B. Medialogiya kak sintez nauk // Kul'tura i iskusstvo. 2012. № 6. S. 71-83.

7. Smirnov E.V. Mashina T'yuringa i chelovek: ontognoseologicheskii aspekt komp'yuternoi metafory soznaniya // Filosofiya i kul'tura. 2012. № 3. S. 115-123.

8. Smorkalov A.Yu., Sadovin I.A. Sistema perenosa lektsii v virtual'nyi mir vAcademia s ispol'zovaniem vozmozhnostei Microsoft Kinect i potokovykh protsessorov // Programmnye sistemy i vychislitel'nye metody. 2013. № 4. S. 354-362.

9. Khanolainen D.P. Estetika vosproizvodimogo v sovremennom iskusstve // Filosofiya i kul'tura. 2013. № 11. S. 1598-1606.

10. Yukhvid A.V. Filosofsko-metodologicheskaya kontseptsiya virtuologii // Filosofiya i kul'tura. 2010. № 9. S. 81-85.

11. Yukhvid A.V. Virtual'nyi teatr: filosofiya, iskusstvo i tekhnologiya XXI veka // Filosofiya i kul'tura. 2010. № 10. S. 94-98.

12. Lopes D. A Philosophy of Computer Art. London: Routledge, 2009.

13. Manovich L. On totalitarian interactivity (notes from the enemy of the people), 1996. (http://manovich.net/ TEXT/totalitarian.htm). 